\title{
Volatile organic compounds: plant natural defense mechanisms against herbivorous arthropods and an opportunity for plant breeding of cotton
}

\author{
Ronald Villamar-Torres ${ }^{1,2, *}$; Seyed Mehdi Jazayeri ${ }^{3}$; Gabriel Liuba-Delfini ${ }^{4,5}$; Luz \\ Cecilia García Cruzaty ${ }^{6}$; Christopher-Robin Viot ${ }^{2}$ \\ Secretaría Nacional de Educación Superior, Ciencia, Tecnología e Innovación, (SENESCYT), ECUador. \\ CIRAD, UMR AGAP, F-34398 Montpellier, France. \\ 3 Universidad Nacional de Colombia - Sede Bogotá, Departamento de Biología. \\ 4 Universidad Técnica Estatal de Quevedo, Ecuador. \\ Universidad Nacional de Colombia - Sede Palmira, Programa de Doctorado en Ciencias Agrarias. \\ 6 Universidad Técnica de Manabí. Facultad de Ingeniería Agronómica, Ecuador.
}

Received February 3, 2018. Accepted June 3, 2018.

\begin{abstract}
Plants' natural defense mechanisms against herbivorous arthropods include the emission of volatile organic compounds (VOC). Nowadays field observations about plant-insect interactions are better understood thanks to the increasingly scientific investigations over recent decades. There are now more precise data about molecules, action modes and physiological and genetic bases of these plant defense mechanisms. VOC present an important potential for crop protection and pesticide use reduction. In the present review, we focus on the latest research advances about plant protection provided by VOC, considering experimental methods of volatile analysis and the involved genes toward genetic improvement of natural defense in the future varieties, particularly for Upland cotton Gossypium hirsutum.
\end{abstract}

Keywords: stress; insect; terpene; secondary metabolites; Gossypium hirsutum.

\section{Introduction}

Plants can produce a high diversity of volatile organic compounds (VOC). The emission of these secondary metabolites can be strongly increased as a result of certain biotic or abiotic stresses (Dicke and Baldwin, 2010; Dong et al., 2016; Schoonhoven et al., 2005). Several VOC are emitted as a natural defense mechanism (NDM) against the attack of arthropods and pathogens (Dicke and Baldwin, 2010; Rodriguez-Saona and Frost, 2010; War et al., 2012). VOC play an important role in communication between plants, as well as with animals (Dicke and Baldwin, 2010). Particularly, many evidences show that the attack of herbivore arthropods induces the emission of VOC with repellent effect on other arthropods (Krempl et al., 2016; Zhou et al., 2013), or with attractive effect for predators of herbivorous arthropods (carnivores, egg and larvae consumers)
(Turlings et al., 1990; D'Alessandro and Turlings, 2005; Erb et al., 2009). Researchers have also noted that protection against herbivore attack extends to neighboring plants from which they were initially attacked (Arimura et al., 2002; Kost and Heil, 2006).

In some regions of the world, despite of attempts to combat insect pests by pesticides, they are still considered one of the main causes of economic losses in crop production (Oliveira et al., 2014). Several scientific research efforts to improve pest management have been carried out. On the other hand, other relevant aspects such as global climate change, land use, biological invasions, conservation of genetic resources and food security are also considered in plant protection programs (Brévault et al., 2014). Many observations confirm the use of VOC-based NDMs as a tool to combat herbivores (Alborn et al., 1997; Chen, 2008; Huang et al., 2015; 
Köllner et al., 2008; Köpke et al., 2008; Robert et al., 2013; War et al., 2011). However, many questions remain to be solved in order to achieve a total understanding of these self-protection tools that are very peculiar to plants (Paré and Tumlinson, 1999). Regarding to its aromatic characteristics, these are determined by the profiles of each VOC, and may vary depending on each genotype (lijima, 2014). During the last two decades several researchers have aroused their interest in the study of NDM, which has allowed several researches to be carried out at the genetic, biochemical, physiological and ecological level (Alborn et al., 1997; Atiama-Nurbel et al., 2015; Bernasconi et al., 1998; Catola et al., 2018; D’Alessandro and Turlings, 2005; Loughrin et al., 1994; Schnee et al., 2006; Ton et al., 2007). Considering discernment of the functionality of VOC, encouraging results could be obtained to achieve a better management of pests in crops, and in effect, decrease dependence on the large quantities of insecticides used to control phytophagous insects (War et al., 2012).

Upland cotton (Gossypium hirsutum) is a tetraploid annual crop and the most cultivated worldwide (d'Eeckenbrugge and Lacape, 2014). From planting to production, it is attacked by a large number of pests, which requires a high consumption of synthetic phytosanitary products to control herbivorous arthropod populations (Villamar-Torres et al., 2016). Consequently, its production is considered to be highly dangerous for the environment and farmers (Renou et al., 2012). Some evidence shows that plant breeding could provide possible answers by VOC to increase their NDM in cotton cultivation, in order to obtain new and improved varieties. This review addresses some relevant aspects of VOC, detailing certain advances generated in recent years in the different studies on these volatile molecules, due to the progress of the technologies used such as genomics and transcriptomics. The techniques used to capture of VOC, both in the field and in greenhouse experiments have advanced, which has allowed study VOC' biosynthesis, their biochemical profiles and some genes linked to their emission, in a better way. Finally, a vision regarding the future perspectives of the uses and applications of VOC as NDM in modern agriculture, particularly against the attack of herbivorous arthropods in cotton cultivation is presented.

Natural defenses: herbivores induce the synthesis of VOC

Plants' NDMs can be direct or indirect (Bruce et al., 2010; Dicke and Baldwin, 2010; Loreto et al., 2014; Rodriguez-Saona and Frost, 2010; War et al., 2012). The former are mediated by characteristics that affect the biology of herbivores, among them the best known are appearing villi, spines, wax, trichomes and leaves with greater thickness, or in turn, the production of toxic molecules such as terpenes, alkaloids, anthocyanins, phenols and quinones (War et al., 2012; 2011).

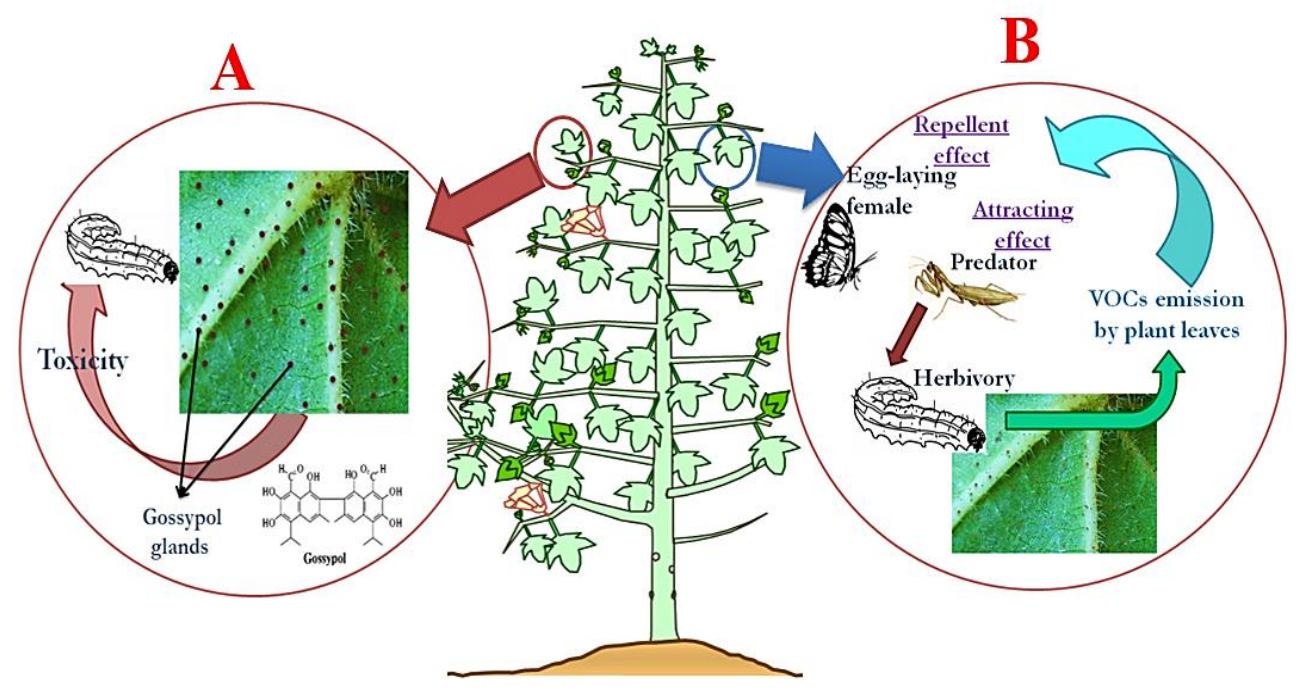

Figure 1. A) Direct mechanism of natural defense in the cotton plant: gossypol glands containing highly toxic terpenoids affecting the physiology of the herbivorous arthropods and causing mortality or retarded growth, B) Indirect mechanism of natural defense by means of volatile organic compounds (VOC) in the cotton plant. It modifies the behavior of certain pests and predators aiming attraction of arthropod-pest enemies and repulsion of arthropods seeking to put their eggs. 
A well-known example of this system are glands emitting gossypol, a highly toxic sesquiterpenoid found in the leaves of cotton plants (Gossypium hirsutum), and are considered a direct NDM due to mortality or retarded growth (Câmara et al., 2016; Hagenbucher et al., 2017; Leghari et al., 2001; Gershenzon and Dudareva, 2007; Krempl et al., 2016). This system has been extensively investigated also in other crops of interest during the last decades (Figure 1A).

On the other hand, plants also possess less evident defense systems, considered as indirect NDM, which imply the emission of chemical messages that influence the behavior of certain herbivores, their predators and even other plants cohabiting with them (D'Alessandro and Turlings, 2005; Huffaker et al., 2013; Villamar-Torres et al., 2016) . It seems that these volatile mixtures exert on plants a function of repellency, and consequently they allow distancing female arthropods having eggs. Additionally, these signals or messages serve as an attraction for enemies of certain arthropods. As evidenced in rice, through the emission of around 30 volatiles, including MeSA (Methyl salicylate) and MeBA (Methyl benzoate), they attracted certain predators of the insect Spodoptera frugiperda (Bruinsma et al., 2008; Kessler and Halitschke, 2007; Pinto-Zevallos et al., 2018). These molecules have seductive characteristics of natural enemies and were also reported in bean, (Phaseolus Iunatus) and Arabidopsis (Chen et al., 2003; War et al., 2012). Potentially, this NDM has many benefits in different aspects (Figure 1B).

Description, biosynthesis of VOC and classification of terpenes

Plant volatiles are metabolites that have low molecular weight and boiling point, approximately $<300 \mathrm{Da}$ and $<260^{\circ} \mathrm{C}$, respectively. Plants are capable of emitting VOC from some of their organs, including leaves, flowers, fruits, and roots; the latter scatter them in atmosphere and soil.

Therefore, all these characteristics allow plants to have an adequate interaction with other organisms and their environment in general (Dong et al., 2016; Negre-Zakharov et al., 2009). In terms of their diversity, to date, about 1700 volatile compounds from more than 90 plant families are known, belonging to both angiosperms and gymnosperms. Globally they include only $1 \%$ of all plant-specific metabolites (Dong et al., 2016; Dudareva et al., 2013; Knudsen et al., 2006).
According to their structural chemical classification VOC are formed by alcohols, hydrocarbons, ketones, aldehydes, ethers and esters (Dong et al., 2016). Based on their biosynthesis in plants, VOC have their origin from precursor primary metabolites, and are subject to the availability of carbon, nitrogen, sulfur, as well as, the energy that comes from these precursors, including but not limited to Acetyl-CoA, Pyruvate, phosphoenolpyruvate (PEP) and erithrose 4-phosphate (Ery4P). Metabolic routes including Shikimate/phenylalanine, methyleritritol phosphate (MEP), mevalonic acid (MVA) and lipoxygenase (LOX), are those from which the emissions of VOC such as phenylpropanoid/benzenoid, all terpenoids I terpenes, methyl jasmonate, volatile derived from green leaves, carotenoids and certain derived fatty acids are derived (Figure 2) (Dudareva et al., 2013). A large amount of VOC derives from biosynthetic pathways of terpenes or terpenoids more specifically from monoterpenes, sesquiterpenes and diterpenes as the most representative VOC in plants (Table 1) (Chen et al., 2003; Dudareva et al., 2013).

Based on their biosynthesis, this could be summarized in four main phases among the vast majority of plants. The first phase consists of the synthesis of IPP (isopentenyl pyrophosphate) that comes from the isomerization in dimethylalylpyrophosphate (DMAPP). It is formed in the classic metabolic route of mevalonate (MEV) within the cytoplasm or mitochondria, although it can also to be formed, on the metabolic pathway of methyleritritol 4-phosphate (MEP) (Dudareva et al., 2013; Rohmer, 2009). The second phase starts from the condensation of molecules by prenyltransferases in order to transfer geranyl diphosphate (GPP; C10), farsenyl diphosphate (FPP; C15), and finally geranylgeranyl diphosphate (GGPP; C20), corresponding predecessors of mono, di and sesquiterpene (Liang et al., 2002). The third phase is where prenyl diphosphates are subject to cyclization reactions catalyzed by several enzymes called terpene synthases (TPS), resulting in base skeletons and transforming the organization of properties created by the precursors (Irmisch et al., 2014; Schwab et al., 2008). Finally, the fourth phase is given by skeleton remodeling through the maturation enzymes of terpenes during the reactions of hydroxylation, oxidation, acylation, double bond deflation and methylation (Dudareva et al., 2013; Pare and Tumlinson, 1997; Schwab et al., 2008). 
As the particular case of cotton (Gossypium spp.), the biosynthesis of mono, sesqui and diterpene does not present great differrences compared to other plants, since the biochemical reactions basically remain the same. From the Geranyl-pyrophosphate GPP synthase that is derived from the IPP/DMAPP, some involved enzymes transform several molecules through some reactions such as cyclization, hydroxylation and dehydration (Yang et al., 2013a).

On the other hand, TPS in general have been divided into three different classes and according to their phylogenetic relationship in seven sub-families. All these subfamilies have been clearly confirmed by functional studies in some plants such as Solanum Iycopersicum (Falara et al., 2011), Populus trichocarpa (Irmisch et al., 2014), Vitis vinifera (Martin et al., 2010), Eucalyptus grandis and $E$. globulus (Külheim et al., 2015) and Arabidopsis thaliana (Aubourg et al., 2002). According to the classification by their classes, class $I$ covers TPS-c (copalyl diphosphate and entkaurene), TPS-e/f (ent-kaurene and in other cases diterpenes as well as mono- and sesquiterpenes) and TPS- $h$ (Selaginellaspecific). These types of genes comprise between 12-14 introns and 13-15 exons. Consecutively, TPS-d belongs to Class II (gymnosperm-specific), which comprises 9 introns and 10 exons. Finally, Classe III includes TPS-a (sesquiterpenes), TPS-b (cyclic monoterpenes and hemiterpenes) and TPS-g (acyclic monoterpenes) and are the class with the highest presence in plants, with 6 introns and 7 exons. A new class of terpene synthesis was reported in Selaginella moellendorffii, and named "microbial terpene synthesis genes", due to its similarity to the microbial synthesis of terpenes or terpenoids (Chen et al., 2011; Külheim et al., 2015; Padovan et al., 2012; Trapp and Croteau, 2001).

Collection, extraction, and analysis of VOC Different techniques for micro-extraction and VOC analysis have been developed (Azmir et al., 2013; Fothergill, 1968; Kallenbach et al., 2014; Lampson et al., 2014; Loreto et al., 2014; Ormeño et al., 2011; Spietelun et al., 2010; Tholl et al., 2006; Van Bramer and Goodrich, 2015; Yang et al., 2013). Although all the systems try to identify the profile of plant volatile compounds, however, the appropriate choice of system to be used in each experiment will often depend on the biological problems and the plant material under study. On the other hand, an important point to consider by researchers is the cost of establishing some techniques for capturing VOC, although in many cases it is better to develop the devices using readily available materials. Although, different devices to capture VOC in several plants have been created; but in general, the principle workflow remains the same (Figure 3).

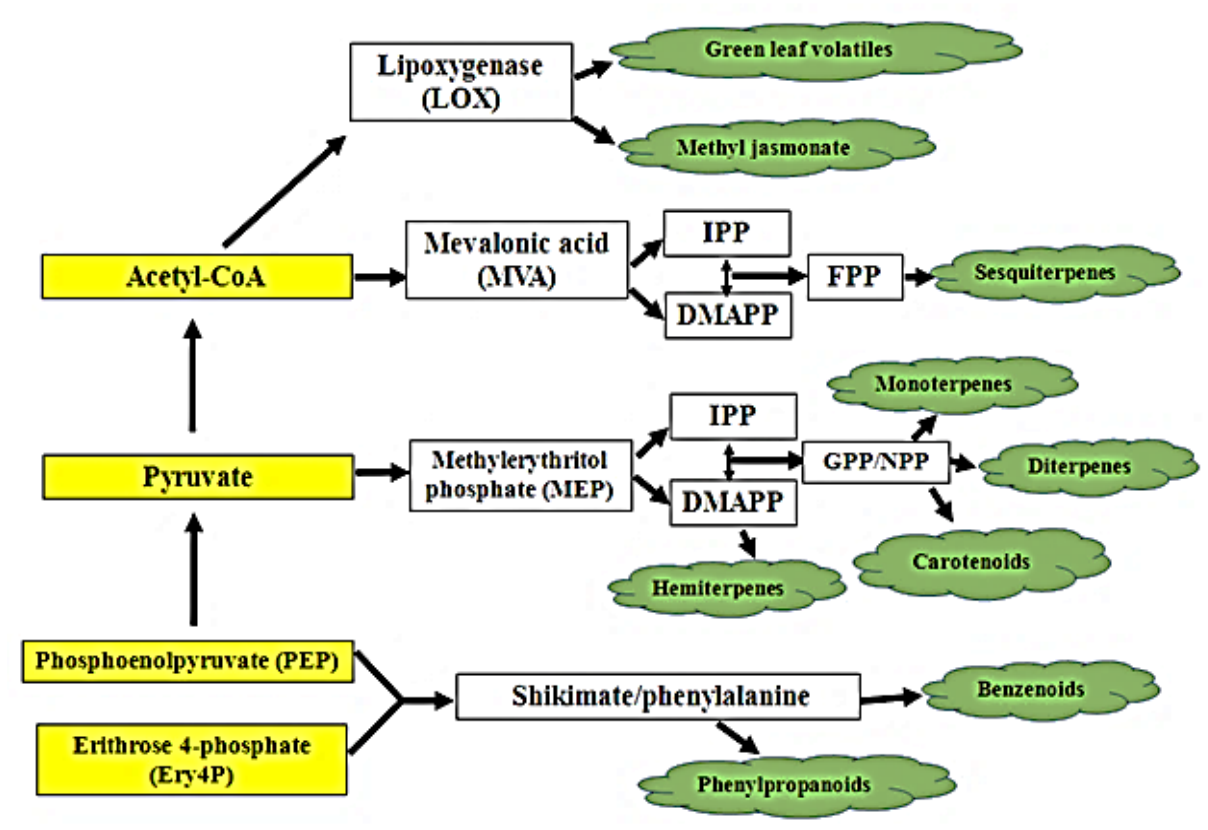

Figure 2. General view of biosynthesis processes that handle VOC emission in plants. IPP: isopentenyl pyrophosphate, FPP: farsenyl diphosphate, DMAPP: dimethylalyl-pyrophosphate, GPP: geranyl diphosphate, NPP: neryl pyrophosphate. 
Table 1

Main groups of VOC terpenes produced in plants with some of their characteristics

\begin{tabular}{clll}
\hline \multicolumn{1}{c}{ Groups } & Most common VOC terpenes & \multicolumn{1}{c}{ Precursors } & Functional characteristics \\
\hline & $\begin{array}{l}\text { B-Myrcene, B-Ocimene, } \\
\text { Limonene, } \alpha \text {-Pinene, ß- } \\
\text { Pinene, Geraniol, Linalool }\end{array}$ & Metabolic pathway MEP & $\begin{array}{l}\text { Pollinator attractant emit } \\
\text { signals to herbivores }\end{array}$ \\
Sesquiterpenes (C15) & $\begin{array}{l}\text { Farnesol, } \text { F- } \\
\text { Farnesene,Nerolidol, } \\
\text { Gossypol, farnesene } \\
\text { cadinene, ß- Cariofilene }\end{array}$ & Metabolic pathway MVA & $\begin{array}{l}\text { Pollinator attractant emit } \\
\text { signals to herbivores, } \\
\text { antimicrobial activity }\end{array}$ \\
Homoterpenes (C5) & DMNT, TMTT, Isoprene & Metabolic pathway MEP & $\begin{array}{l}\text { Emission of signals to } \\
\text { herbivores }\end{array}$ \\
\hline
\end{tabular}

Two method types for VOC capture are mainly used static and dynamic. Of these, the first is more classic and simple; however, it is less efficient when capturing VOC, because once captured molecules are diluted inside the chamber, consequently, the headspace, accumulates humidity and heat. This occurs especially when the samples are collected under solar or artificial lighting that can directly interfere with normal physiology and the emission of plant volatiles. Its use is recommended for the study of VOC profiles in a single space of time and not in several time frequencies where VOC emissions are changing. It is mainly used to capture VOC in fruits (lijima, 2014; Ormeño et al., 2011; Tholl et al., 2006).

Dynamic headspace sampling technique is presented as the most used for almost all areas of VOC collection. This method consists in allowing the flow of continuous air through a sampling container where the VOC accumulate in gas that enters and exits through attached holes in each end of the containers (one as air intake and one as exit). It is connected by means of fine hoses to a vacuum pump (Loreto et al., 2014; Tholl et al., 2006). While VOC are trapped in absorbents and the gas circulates through the container, it allows the collection of sufficient VOC for detection. This system prevents the accumulation of moisture due to temperature increase, unlike the static system; however, it is important to make sure that clean air is being provided when pumping air through fluids, using carbon filters for example, in order to avoid VOC impurities moving to the following analytical parts (Tholl et al., 2006). This system is mainly used for synthesis elucidation studies of volatiles affected primarily by environmental events, such as flowering, attack by herbivores, and other biotic and abiotic factors (lijima, 2014; Loreto et al., 2014).

Apart of the two techniques used for collection of VOC, these mixtures are trapped by micro-extraction fibers in solid phase (SPME), due to the advantages of this system, which is capable to detect a large number of molecules, even the smallest ones. This decreases loss of VOC amounts at the time of extraction and analysis (lijima, 2014; Azmir et al., 2013; Loreto et al., 2014). Latest evidence shows that an adequate choice of fiber can be highly significant when extracting VOC (lijima, 2014; Kusano et al., 2013; Risticevic and Pawliszyn, 2013).

Divinylbenzene/carboxen/polyDimethylsiloxane fibers have been reported to be suitable for metabolic studies and to provide optimal extraction coverage and sensitivity with a wide range of analyzes (lijima, 2014; Risticevic and Pawliszyn, 2013).

With regard to the characterization of VOC, gas chromatography (GC) is employed. This technique is used to separate and analyze the profiles of analytes (the name given to each VOC), which are evaporated and treated without decomposition. Additionally, during the first phase called preparative chromatography, GC can help identify a particular compound (Azmir et al., 2013; Tholl et al., 2006; Yang et al., 2013b). Regarding to its functionality, the chromatograph uses a flow tube through which the different VOC circulate by means of a carrier gas, according to its denomination. This phase is known as the mobile phase. Then, the analytes reach to differential speeds depending on VOC' chemical and physical properties, the latter process is called the stationary phase. After that, the samples are injected as solvent extracts, which allow them to heat up and separate and then be placed in a thermal desorption tube, this whole process occurs at a temperature of 250 $300{ }^{\circ} \mathrm{C}$. Next, the VOC are released and condensed in a cold trap and then injected into the GC column. For purely analytical purposes, the volatiles are separated into capillary columns of fused silica, with different stationary phases. Depending on column selection, relevant and detailed information are available in the market. 


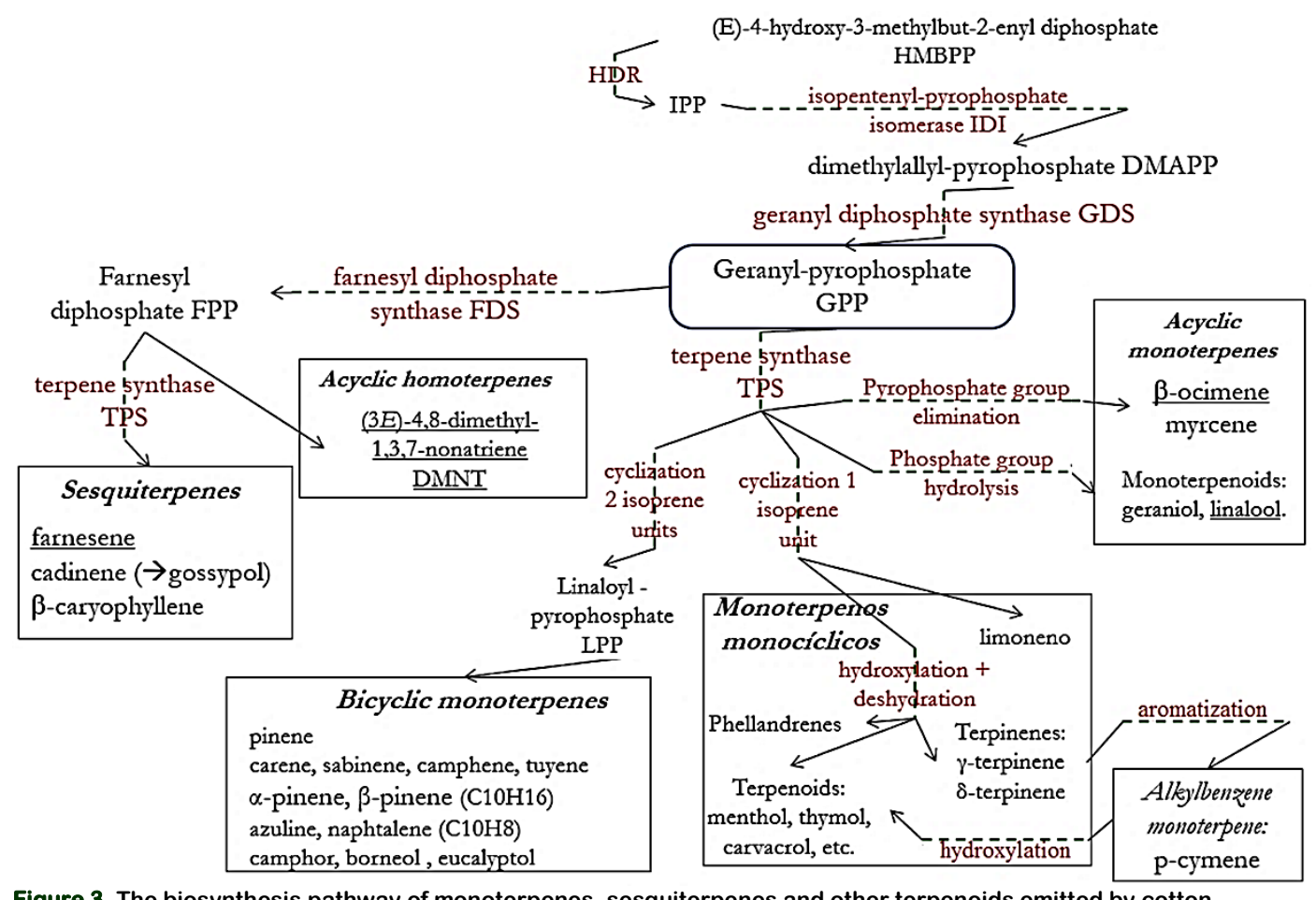

Figure 3. The biosynthesis pathway of monoterpenes, sesquiterpenes and other terpenoids emitted by cotton.

For plant-based study of the emission of VOC terpenes, the photoionization detector (PID) is used, which is considerably more sensitive to the detection of compounds with the presence of double bonds Finally, mass spectrometry (MS), a device that separates the atomic nuclei with respect to the relationship between mass and charge $(\mathrm{m} / \mathrm{z})$ is available. Globally, it allows adequate studies on the composition of chemical elements and atomic isotopes. It usually works in conjunction with the GC, as GC-MS. The process done by MS consists in heating a beam of the under study compound up to vaporize and ionize the different atoms, consequently; a detector functions as a specific pattern for each analyte. It has being widely used for VOC analysis in plants (Risticevic and Pawliszyn, 2013; Tholl et al., 2006; Van Bramer and Goodrich, 2015; Vas and Vékey, 2004).

There is a great diversity of synthesis of compounds in plants that have been characterized by the techniques. In the cotton plant (Gossypium hirsutum), some VOC have been characterized such as Gossypol, (E) B-Ocimene, linalool, (E)-4,8Dimethyl-1,3,7-Nonatriene, (E, E)-a Farnesene, (E)-b-Farnesene, (E, E)-4,8,12Trimethyl-1,3,7,11-Tridecatetraene (Brévault et al., 2014), $\alpha$-Pinene, $\beta$-Pinene, (E) -b-caryophyllene, (p) -cymene, particularly linked to the biosynthesis of monoterpenes, sesquiterpenes and terpenoids as previously mentioned (Figure 4) (Huang et al., 2013). Additionally, specific VOC capture devices for this crop have been manufactured in order to facilitate the collection and subsequent analysis of VOC, the vast majority of which are used in studies of attack and induction of herbivores (Lampson et al., 2014; Rose et al., 1996).

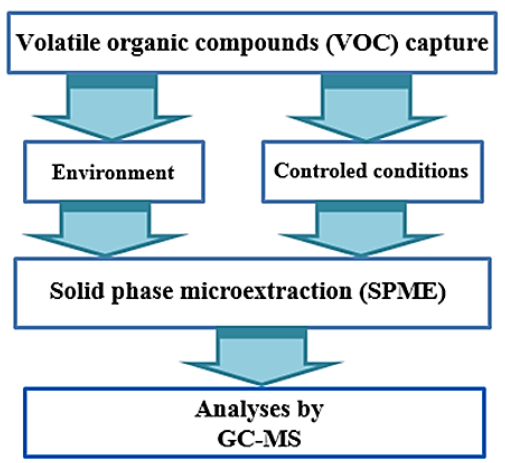

Figure 3. General workflow of VOC capture. GC-MS: Gas chromatography-mass spectrometry.

The new era of omics tools as support for genetic improvement

Thanks to the advance of fields such as functional and comparative genomics, transcriptomics and proteomics, VOC for their protective potential have been successfully studied in a better way at the molecular genetic level. Thus, the presence of genes leading some metabolic processes 
and linked to some enzymes of interest has been proven in several genomes. To date, in $A$. thaliana, 40 terpene synthesis genes have been reported; of which 32 are considered functional genes while 8 are pseudogenes. According to their phylogeny, it is confirmed that they are highly related to monoterpenes, sesquiterpenes and diterpenes (Aubourg et al., 2002). Another example is the grape (Vitis vinifera), which contains 69 putative functional genes, 20 partial and 63 pseudogenes, which were found in a study of functional annotations, genome organization and phylogeny of the gene family of terpene synthesis in 2010 (Martin et al., 2010). Finally, in the balsamic poplar (Populus trichocarpa) 38 genes of the terpene family coded by putative proteins of an approximate length of 520 amino acids, tomato 44 terpene genes, including 29 functional ones, Eucalyptus 113 terpene genes, of which 106 highly functional have been reported (Külheim et al., 2015).

On the other hand, for some varieties because of plant improvement breeding, yield have increased while having acquired resistance to certain stresses in their natural state but their production of VOC has decreased, which makes them more susceptible to any attack of herbivorous. Latest evidence in transgenic $B t$ cotton indicated that the production of sesquiterpene gossypol is diminished by "Cry" proteins of Bacillus thuringiensis (Bt) those are efficient in the control of Lepidoptera (Hagenbucher et al., 2017). For some plants such as $\boldsymbol{A}$. thaliana there are evidences of resistance to attack by herbivores. For example transgenic Arabidopsis showing high overexpression of a strawberry terpene synthase gene, responsible for the production of alcohol (3S)-(E)-nerolidol was reported to attract the carnivorous mite (Phytoseiulus persimilis) (Kappers et al., 2005; War et al., 2012). Additionally, it was found that the synthesis of green leaf volatiles (GLV), which originate from the primary precursor Acetyl-CoA and are synthesized through the hydroxypropylide of lyoxygenase (HPL), increased after herbivory by white cabbage butterfly larvae and pathogen infection (gray mold), compared to Arabidopsis wild type (Shiojiri et al., 2006). In maize (Zea mays), after herbivory by lepidoptera, the production of attractive volatiles for females of several species of parasitic wasps increased. These molecules are encoded by the TPS10 gene, previously reported in Arabidopsis (Kappers et al., 2005), forming (E)- $\beta$-farnesene, (E)- $\alpha$ - bergamotene, and other sesquiterpene hydrocarbons that are induced from farnesyl diphosphate (Dong et al., 2016; Schnee et al., 2006).

All these available technologies have allowed to explore slightly the genetic resources of some cultivated species (mostly maize), depending on their capacity to produce VOC (Degen et al., 2004), contrasting mainly modern, semi-wild and wild varieties (Köllner et al., 2008). For the semi and wild varieties, a large amount of valuable genetic information about the genes related to environmental adaptation and, particularly, resistance and tolerance to attack by herbivores (Viot, 2016) could be hidden and undisclosed. This makes it necessary to continue exploring the NDMs to learn more in details about genes that lead some metabolic routes at the time of herbivory attack like what seen for TPS10 in Arabidopsis (Kappers et al., 2005). Some strategies based on the positioning of QTLS along genetic maps, nowadays are used for gene selection as this approach has outputted good results in animal genetic improvement (Viot, 2016).

Expression profiles in response to stresses have generated reliable and accurate results. RNA-seq allows us to study many genes that show differential expression pattern while overexpression or downregulation by the effect of undesirable conditions. This technology produces millions of short sequence reads for purified mRNA, based on sequencing on a high performance platform or NGS such as llumina, Ion Torrent, ABI, SOLID or PacBio (Shendure and $\mathrm{Ji}, 2008$ ), routinely being applied to analysis of genomes, epigenomes and transcriptomes (Jazayeri and VillamarTorres, 2017; Oshlack and Robinson, 2010; Griffith et al., 2015; Jazayeri et al., 2015).

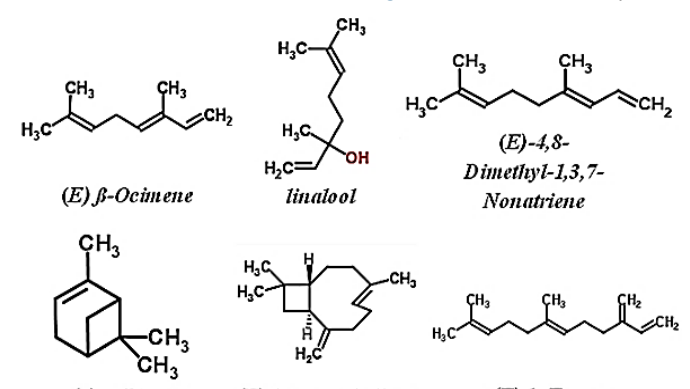

(土)-a-Pinene

(E)-b-caryopliyllene

(E)-b-Fantesene

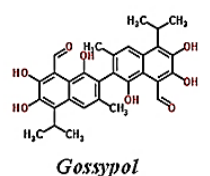

Figure 4. Chemical structure of some molecules of monoterpens, sesquiterpens and other terpenoides characterized in cotton. 


\section{A case study, cotton}

In West Africa millions of small farmers depend on cotton production (Gossypium hirsutum) (Brévault et al., 2014). Normally, cotton production in this region has been characterized by a low consumption of synthetic insecticides, however, in recent years there has been a high resistance of certain herbivores especially cotton worm to the use of pyrethroids (Brévault et al., 2014; Renou et al., 2012). Consequently, all these have led the researchers to initiate studies on plant - herbivore interaction and return to the exploration of NDMs to understand their function, activity, and operation. At the end, these characteristics are used for genetic improvement of new cotton varieties, but only to a field-level (classical plant breeding), which could take several years up to obtain improved varieties. However, in cotton (Gossypium hirsutum) there are not many studies on the genomic and molecular bases of herbivore NDM, and how these defenses are orchestrated at the level of internal molecular biological processes (Huang et al., 2015). A few transcriptomic researches have reported that cotton plants show differential expression, where several genes are overexpressed or downregulated at the time of attack by arthropod insects. So that, some genes and proteins have been able to be characterized, when are subjected to attack of insects such as Helicoverpa armigera, Aphis gossypii and Bemisia tabacci (Whitefly), arthropods that cause high economic losses in cotton plantations (Dubey et al., 2013; Huang et al., 2015; Zhou et al., 2013).

\section{Perspectives futures}

Based on an adequate use of all the tools available and detailed in this review, combined with the use of molecular genetics in laboratories, good omens could be envisaged to improve plant protection, particularly cotton cultivation. Understanding functions of some genes linked to VOC that are leading processes or metabolic pathways can provide key answers, allowing identifying future potentialities and probable solutions to solve problems due to herbivore attacks. In the Figure 6 is showed a by-plan suggested for a plant breeding program based in cotton, with the combination of plant genomics and metabolic, followed by molecular validation of genes, proteins, and enzymes. Finally, until obtaining the improved varieties with the support of MAS (Molecular Assisted Selection).

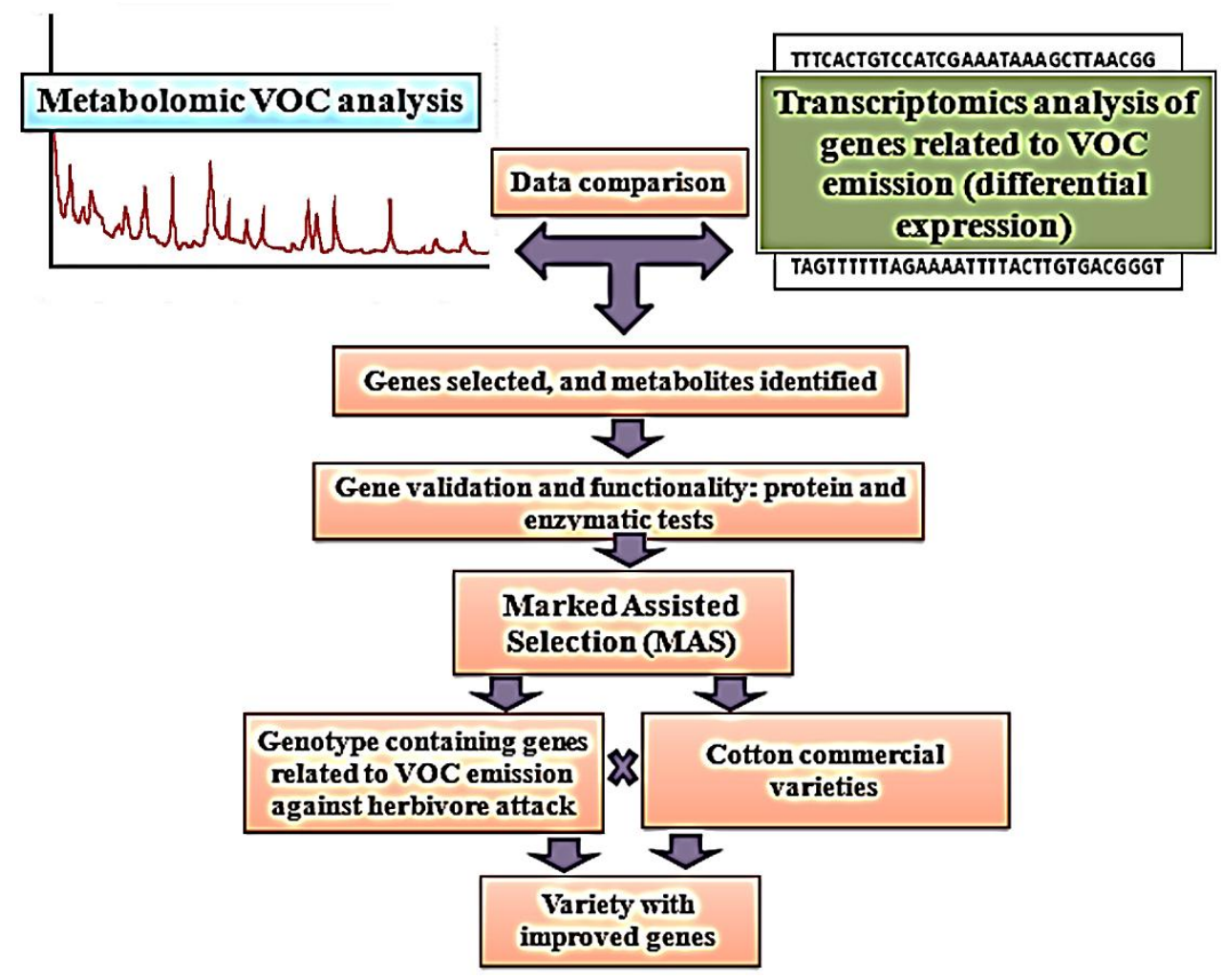

Figure 5. An overview of biotechnological tools for plant breeding based on VOC as self-defense mechanism against herbivores suggested in cotton crop. 


\section{Conclusions}

All these advantages show the possibility of supporting with the use of agricultural biotechnology to create varieties in relation to NDM against predatory arthropods, mainly in the cotton and in benefit of small farmers, hence, avoiding a high consume of pesticides which representing a hazard for environment and for the health of the cotton cultivators.

\section{Acknowledgments}

The present manuscript forms part of a doctoral thesis developed in the Genomics and Selection Team of the Mixed Unit for Research on Genetic Improvement and Plant Adaptation (UMR AGAP) of the Center for International Cooperation in Agronomic Research for Development (CIRAD) linked to the GAIA Doctorate School of the University of Montpellier, France. In addition, the author RVT thanks the Government of Ecuador for the funding obtained through the Secretariat of Higher Education, Science, Technology, and Innovation (SENESCYT), for his doctoral studies, as well as to partially finance the research work developed within the framework of his doctoral program.

\section{References}

Alborn, H.T.; Turlings, T.C.J.; Jones, T.H.; Stenhagen, G.; Loughrin, J.H.; Tumlinson, J.H. 1997. An Elicitor of Plant Volatiles from Beet Armyworm Oral Secretion. Science 276(5314): 945-949.

Arimura, G.; Ozawa, R.; Nishioka, T.; Boland, W.; Koch, T.; Kuhnemann, F.; Takabayashi, J. 2002. Herbivore-induced volatiles induce the emission of ethylene in neighboring lima bean plants. Plant $J$, 29.

Atiama-Nurbel, T.; Quilici, S.; Boyer, E.; Deguine, J.-P.; Glenac, S.; Bialecki, A. 2015. Volatile Constituents of Cucumis sativus. Chemistry of Natural Compounds 51(4): 771-775.

Aubourg, S.; Lecharny, A.; BohImann, J. 2002. Genomic analysis of the terpenoid synthase (AtTPS) gene family of Arabidopsis thaliana. Mol Genet Genomics 267(6): 730-745.

Azmir, J.; Zaidul, I.S.M.; Rahman, M.M.; Sharif, K.M.; Mohamed, A.; Sahena, F.; Jahurul, M.H.A.; Ghafoor, K.; Norulaini, N.A.N.; Omar, A.K.M. 2013. Techniques for extraction of bioactive compounds from plant materials: A review. Journal of Food Engineering 117(4): 426-436.

Bernasconi, M.L.; Turlings, T.C.J.; Ambrosetti, L.; Bassetti, P.; Dorn, S. 1998. Herbivore-induced emissions of maize volatiles repel the corn leaf aphid, Rhopalosiphum maidis. Entomologia Experimentalis et Applicata 87(2): 133-142.

Brévault, T.; Renou, A.; Vayssières, J.-F.; Amadji, G.; Assogba-Komlan, F.; Diallo, M. D.; ... Clouvel, P. 2014a. DIVECOSYS: Bringing together researchers to design ecologically-based pest management for small-scale farming systems in West Africa. Crop Protection 66: 53-60.

Bruce, T.J.A.; Midega, C.A.O.; Birkett, M.A.; Pickett, J.A.; Khan, Z.R. 2010. Is quality more important than quantity? Insect behavioural responses to changes in a volatile blend after stemborer oviposition on an African grass. Biology Letters 6(3): 314-317.

insma, M.; IJdema, H.; Van Loon, J.J.A.; Dicke, M. 2008. Differential effects of jasmonic acid treatment of Brassica nigra on the attraction of pollinators, parasitoids, and butterflies. Entomologia Experimentalis et Applicata 128(1): 109-116.

Câmara, A.C.L.; do Vale, A.M.; Mattoso, C.R.S.; Melo, M.M.; Soto-Blanco, B. 2016. Effects of gossypol from cottonseed cake on the blood profile in sheep. Tropical Animal Health and Production 48(5): 1037 1042.

Catola, S.; Centritto, M.; Cascone, P.; Ranieri, A.; Loreto, F.; Calamai, L.; Balestrini, R.; Guerrieri, E. 2018. Effects of single or combined water deficit and aphid attack on tomato volatile organic compound (VOC) emission and plant-plant communication. Environmental and Experimental Botany 153: 54-62.

Chen, F.; Tholl, D.; Bohlmann, J.; Pichersky, E. 2011. The family of terpene synthases in plants: a mid-size family of genes for specialized metabolism that is highly diversified throughout the kingdom. The Plant Journal 66(1): 212-229.

Chen, F.; Tholl, D.; D’Auria, J.C.; Farooq, A.; Pichersky, E.; Gershenzon, J. 2003. Biosynthesis and Emission of Terpenoid Volatiles from Arabidopsis Flowers. The Plant Cell 15(2): 481-494.

Chen, M.-S. 2008. Inducible direct plant defense against insect herbivores: A review. Insect Science 15(2): 101-114.

d'Eeckenbrugge, G.C.; Lacape, J.-M. 2014. Distribution and Differentiation of Wild, Feral, and Cultivated Populations of Perennial Upland Cotton (Gossypium hirsutum L.) in Mesoamerica and the Caribbean. PLOS ONE 9(9): e107458.

D'Alessandro, M.; Turlings, T.C.J. 2005. In Situ Modification of Herbivore-Induced Plant Odors: A Novel Approach to Study the Attractiveness of Volatile Organic Compounds to Parasitic Wasps. Chemical Senses 30(9): 739-753.

Degen, T.; Dillmann, C.; Marion-Poll, F.; Turlings, T.C.J. 2004. High Genetic Variability of Herbivore-Induced Volatile Emission within a Broad Range of Maize Inbred Lines. Plant Physiology 135(4): 1928-1938.

Dicke, M.; Baldwin, I.T. 2010. The evolutionary context for herbivore-induced plant volatiles: beyond the 'cry for help.' Trends in Plant Science 15(3): 167175.

Dong, F.; Fu, X.; Watanabe, N.; Su, X.; Yang, Z. 2016. Recent Advances in the Emission and Functions of Plant Vegetative Volatiles. Molecules 21(2): 124.

Dubey, N.K.; Goel, R.; Ranjan, A.; Idris, A.; Singh, S.K.; Bag, S.K.; Chandrashekar, K.; Deo-Pandey, K.; Kumar-Singh, P.; Sawant, S.V. 2013. Comparative transcriptome analysis of Gossypium hirsutum $\mathrm{L}$. in response to sap sucking insects: aphid and whitefly. BMC Genomics 14: 241.

Dudareva, N.; Klempien, A.; Muhlemann, J.K.; Kaplan, I. 2013. Biosynthesis, function and metabolic engineering of plant volatile organic compounds. New Phytologist 198(1): 16-32.

Erb, M.; Lenk, C.; Degenhardt, J.; Turlings, T. C. J. 2009. The underestimated role of roots in defense against leaf attackers. Trends in Plant Science 14(12): 653659.

Falara, V.; Akhtar, T.A.; Nguyen, T.T.H.; Spyropoulou, E.A.; Bleeker, P.M.; Schauvinhold, I.; Pichersky, E. 2011. The tomato terpene synthase gene family. Plant Physiology 157(2): 770-789.

Fothergill, W.T; 1968. Gas chromatography. Technique. Proceedings of the Royal Society of Medicine 61(5): 525-528.

Gershenzon, J.; Dudareva, N. 2007. The function of terpene natural products in the natural world. Nature Chemical Biology 3(7): 408-414.

Griffith, M.; Walker, J.R.; Spies, N.C.; Ainscough, B.J.; Griffith, O.L. 2015. Informatics for RNA Sequencing: A Web Resource for Analysis on the Cloud. PLOS Computational Biology 11(8): e1004393. 
Hagenbucher, S.; Eisenring, M.; Meissle, M.; Romeis, J. 2017. Interaction of transgenic and natural insect resistance mechanisms against Spodoptera littoralis in cotton. Pest Management Science 73: 1670-1678.

Huang, X.; Xiao, Y.; Köllner, T.G.; Zhang, W.; Wu, J.; Wu, J.; Guo, Y.; Zhang, Y. 2013. Identification and characterization of (E)- $\beta$-caryophyllene synthase and $\alpha / \beta$-pinene synthase potentially involved in constitutive and herbivore-induced terpene formation in cotton. Plant Physiology and Biochemistry 73: 302-308.

Huang, X.-Z.; Chen, J.-Y.; Xiao, H.-J.; Xiao, Y.-T.; Wu, J.; Wu, J.-X.; Zhou, J.-J.; Zhang, Y.-J.; Guo, Y.-Y. 2015. Dynamic transcriptome analysis and volatile profiling of Gossypium hirsutum in response to the cotton bollworm Helicoverpa armigera. Scientific Reports 5: 11867.

Huffaker, A.; Pearce, G.; Veyrat, N.; Erb, M.; Turlings, T.C.J.; Sartor, R.; Shen, Z.; Briggs, S.P.; Vaughan, M.M.; Alborn, H.T.; Teal, P.E.A.; Schmelz, E.A. 2013. Plant elicitor peptides are conserved signals regulating direct and indirect antiherbivore defense. Proceedings of the National Academy of Sciences 110(14): 5707-5712.

lijima, Y. 2014. Recent Advances in the Application of Metabolomics to Studies of Biogenic Volatile Organic Compounds (BVOC) Produced by Plant. Metabolites 4(3): 699-721.

Irmisch, S.; Jiang, Y.; Chen, F.; Gershenzon, J.; Köllner, T.G. 2014. Terpene synthases and their contribution to herbivore-induced volatile emission in western balsam poplar (Populus trichocarpa). BMC Plant Biology 14: 270.

Jazayeri, S.M.; Melgarejo-Muñoz, L.M.; Romero, H.M. 2015. RNA-SEQ: a glance at technologies and methodologies. Acta Biológica Colombiana 20(2): 23-35.

Jazayeri, S.M.; Villamar-Torres, R.V. 2017. Genomic and transcriptomic approaches toward plant selection. Journal of Science and Research: Revista Ciencia e Investigación 2(8): 54-64.

Kallenbach, M.; Oh, Y.; Eilers, E.J.; Veit, D.; Baldwin, I.T.; Schuman, M.C. 2014. A robust, simple, highthroughput technique for time-resolved plant volatile analysis in field experiments. The Plant Journal 78(6): 1060-1072.

Kappers, I.F.; Aharoni, A.; Herpen, T.W.J.M.; Luckerhoff, L.L.P.; Dicke, M.; Bouwmeester, H.J. 2005. Genetic engineering of terpenoid metabolism attracts, bodyguards to Arabidopsis. Science 309(5743): 2070-2.

Kessler, A.; Halitschke, R. 2007. Specificity and complexity: the impact of herbivore-induced plant responses on arthropod community structure. Current Opinion in Plant Biology 10(4): 409-414.

Knudsen, J.T.; Eriksson, R.; Gershenzon, J.; Ståhl, B. 2006. Diversity and distribution of floral scent. The Botanical Review 72: 1

Köllner, T. G.; Held, M.; Lenk, C.; Hiltpold, I.; Turlings, T.C. J.; Gershenzon, J.; Degenhardt, J. 2008. A maize (E)- $\beta$-Caryophyllene synthase implicated in indirect defense responses against herbivores is not expressed in most American maize varieties. The Plant Cell 20(2): 482-494.

Köpke, D.; Schröder, R.; Fischer, H.M.; Gershenzon, J.; Hilker, M.; Schmidt, A. 2008. Does egg deposition by herbivorous pine sawflies affect transcription of sesquiterpene synthases in pine? Planta 228(3): 427-438.

Kost, C.; Heil, M. 2006. Herbivore-induced plant volatiles induce an indirect defence in neighbouring plants. Journal of Ecology 94(3): 619-628.

Krempl, C.; Heidel-Fischer, H.M.; Jiménez-Alemán, G.H.; Reichelt, M.; Menezes, R.C.; Boland, W.; Vogel, H.; Heckel, D.G.; Joußen, N. 2016. Gossypol toxicity and detoxification in Helicoverpa armigera and Heliothis virescens. Insect Biochemistry and Molecular Biology 78: 69-77.
Külheim, C.; Padovan, A.; Hefer, C.; Krause, S.T.; Köllner, T.G.; Myburg, A.A.; ... Foley, W.J. 2015. The Eucalyptus terpene synthase gene family. BMC Genomics 16: 450.

Kusano, M.; lizuka, Y.; Kobayashi, M.; Fukushima, A.; and Saito, K. 2013. Development of a Direct Headspace Collection Method from Arabidopsis Seedlings Using HS-SPME-GC-TOF-MS Analysis. Metabolites 3(2): 223-242.

Lampson, B. D.; Khalilian, A.; Greene, J. K.; Han, Y. J.; Degenhardt, D. C.; Lampson, B. D.; ... Degenhardt, D.C. 2014. Development of a Portable Electronic Nose for Detection of Cotton Damaged by Nezara viridula (Hemiptera: Pentatomidae). Journal of Insects 2014: e297219.

Leghari, M.A.; Kalroo, A.M.; Leghari, A.B. 2001. Studies on host plant resistance to evaluate the tolerance/susceptibility against cotton pests. Pakistan Journal of Biological Science 4: 15061508.

Liang, P.-H.; Ko, T.-P.; Wang, A. H.-J. 2002. Structure, mechanism and function of prenyltransferases. European Journal of Biochemistry 269(14): 33393354.

Loreto, F.; Dicke, M.; Schnitzler, J.-P.; Turlings, T.C.J. 2014. Plant volatiles and the environment. Plant, Cell and Environment 37(8): 1905-1908.

Loughrin, J.H.; Manukian, A.; Heath, R.R.; Turlings, T. C.; Tumlinson, J.H. 1994. Diurnal cycle of emission of induced volatile terpenoids by herbivore-injured cotton plant. Proceedings of the National Academy of Sciences of the United States of America 91(25): 11836-11840.

Martin, D.M.; Aubourg, S.; Schouwey, M.B.; Daviet, L.; Schalk, M.; Toub, O.; ... Bohlmann, J. 2010. Functional Annotation, Genome Organization and Phylogeny of the Grapevine (Vitis vinifera) Terpene Synthase Gene Family Based on Genome Assembly, FLcDNA Cloning, and Enzyme Assays. BMC Plant Biology 10: 226.

Negre-Zakharov, F.; Long, M.C.; Dudareva, N. 2009. Floral Scents and Fruit Aromas Inspired by Nature. In A. E. Osbourn and V. Lanzotti (Eds.), Plantderived Natural Products. Springer US. pp. 405431.

Oliveira, C.M.; Auad, A.M.; Mendes, S.M.; Frizzas, M.R. 2014. Crop losses and the economic impact of insect pests on Brazilian agriculture. Crop Protection, 56, 50-54.

Ormeño, E.; Goldstein, A.; Niinemets, Ü. 2011. Extracting and trapping biogenic volatile organic compounds stored in plant species. TrAC Trends in Analytical Chemistry 30(7): 978-989.

Oshlack, A.; Robinson, M.D.; Young, M.D. 2010. From RNA-Seq reads to differential expression results. Genome Biology 11(12): 220.

Padovan, A.; Keszei, A.; Wallis, I.R.; Foley, W.J. 2012. Mosaic Eucalypt Trees Suggest Genetic Control at a Point That Influences Several Metabolic Pathways. Journal of Chemical Ecology 38(7): 914-923.

Pare, P. W.; Tumlinson, J.H. 1997. De novo biosynthesis of volatiles induced by insect herbivory in cotton plants. Plant Physiol, 114.

Paré, P. W.; Tumlinson, J.H. 1999. Plant Volatiles as a Defense against Insect Herbivores. Plant Physiology 121(2): 325-332.

Pinto-Zevallos, D.M.; Bezerra, R.H.S.; Souza, S.R.; Ambrogi, B.G. 2018. Species- and densitydependent induction of volatile organic compounds by three mite species in cassava and their role in the attraction of a natural enemy. Experimental and Applied Acarology 74(3): 261-274.

Renou, A.; Togola, M.; Téréta, I.; Brévault, T. 2012. First Steps Towards "Green" Cotton in Mali. Outlooks on Pest Management 23(4): 173-176.

Risticevic, S.; Pawliszyn, J. 2013. Solid-Phase Microextraction in Targeted and Nontargeted Analysis: Displacement and Desorption Effects. Analytical Chemistry 85(19): 8987-8995. 
Robert, C.A.M.; Erb, M.; Hiltpold, I.; Hibbard, B.E.; Gaillard, M.D.P.; Bilat, J.; ... Zwahlen, C. 2013. Genetically engineered maize plants reveal distinct costs and benefits of constitutive volatile emissions in the field. Plant Biotechnology Journal 11(5): 628639.

Rodriguez-Saona, C.R.; Frost, C.J. 2010. New evidence for a multi-functional role of herbivore-induced plant volatiles in defense against herbivores. Plant Signaling and Behavior 5(1): 58-60.

Rohmer, M. 2009. Mevalonate-independent methylerythritol phosphate pathway for isoprenoid biosynthesis. Elucidation and distribution. Pure and Applied Chemistry 75(2-3): 375-388.

Rose, U.; Manukian, A.; Heath, R.R.; Tumlinson, J.H. 1996. Volatile Semiochemicals Released from Undamaged Cotton Leaves (A Systemic Response of Living Plants to Caterpillar Damage). Plant Physiology 111(2): 487-495.

Schnee, C.; Köllner, T.G.; Held, M.; Turlings, T.C.J.; Gershenzon, J.; Degenhardt, J. 2006. The products of a single maize sesquiterpene synthase form a volatile defense signal that attracts natural enemies of maize herbivores. Proceedings of the National Academy of Sciences of the United States of America 103(4): 1129-1134.

Schoonhoven, L.M.; Loon, J.J.A. van; Dicke, M. 2005. Insect-plant biology.; (Ed.2), xvii + 421 pp.

Schwab, W.; Davidovich-Rikanati, R.; Lewinsohn, E. 2008. Biosynthesis of plant-derived flavor compounds. The Plant Journal 54(4): 712-732.

Shendure, J.; Ji, H. 2008. Next-generation DNA sequencing. Nature Biotechnology 26(10): 11351145.

Shiojiri, K.; Kishimoto, K.; Ozawa, R.; Kugimiya, S. Urashimo, S.; Arimura, G.; ... Takabayashi, J. 2006. Changing green leaf volatile biosynthesis in plants: An approach for improving plant resistance against both herbivores and pathogens. Proceedings of the National Academy of Sciences 103(45): 16672 16676.

Spietelun, A.; Pilarczyk, M.; Kloskowski, A.; Namieśnik, J. 2010. Current trends in solid-phase microextraction (SPME) fibre coatings. Chemical Society Reviews 39(11): 4524-4537.

Tholl, D.; Boland, W.; Hansel, A.; Loreto, F.; Röse, U. S. R.; Schnitzler, J.-P. 2006. Practical approaches to plant volatile analysis. The Plant Journal 45(4): 540 560.
Ton, J.; D’Alessandro, M.; Jourdie, V.; Jakab, G.; Karlen, D.; Held, M.; Turlings, T.C.J. 2007. Priming by airborne signals boosts direct and indirect resistance in maize. The Plant Journal 49(1): 16-26.

Trapp, S.C.; Croteau, R.B. 2001. Genomic Organization of Plant Terpene Synthases and Molecular Evolutionary Implications. Genetics 158(2): 811-832.

Turlings, T.C.J.; Tumlinson, J.H.; Lewis, W.J. 1990. Exploitation of herbivore-induced plant odors by host-seeking parasitic wasps. Science 250.

Van Bramer, S.; Goodrich, K.R. 2015. Determination of Plant Volatiles Using Solid Phase Microextraction GC-MS. Journal of Chemical Education 92(5): 916919

Vas, G.; Vékey, K. 2004. Solid-phase micro-extraction: a powerful sample preparation tool prior to mass spectrometric analysis. Journal of Mass Spectrometry 39(3): 233-254.

Villamar-Torres, R.O.; Liu-Ba, G.A.; Legavre, T.; Viot, C. 2016. Los compuestos orgánicos volátiles, defensa natural del algodón \#Gossypium hirsutum\# mejorable gracias a la biotecnología. CIBB-BA-EO061 [Communication avec actes].

Viot, C. 2016. La biotecnología y su utilización en conservación y caracterización de los recursos genéticos de \#Gossypium barbadense\# y en mejoramiento del algodón. Available in: http://www.ipaperu.org/index.php?option=com_doc manandtask $=$ doc $\_$detailsandgid $=52$ and $/$ te $m i d=76$

War, A.R.; Paulraj, M.G.; Ahmad, T.; Buhroo, A.A.; Hussain, B.; Ignacimuthu, S.; Sharma, H.C. 2012. Mechanisms of plant defense against insect herbivores. Plant Signaling and Behavior 7(10): 1306-1320.

War, A.R.; Sharma, H.C.; Paulraj, M.G.; War, M.Y.; Ignacimuthu, S. 2011. Herbivore induced plant volatiles. Plant Signaling and Behavior 6(12): 19731978.

Yang, C.; Wang, J.; Li, D. 2013a. Microextraction techniques for the determination of volatile and semivolatile organic compounds from plants: A review. Analytica Chimica Acta 799: 8-22.

Yang, C.-Q.; Wu, X.-M.; Ruan, J.-X.; Hu, W.-L.; Mao, Y.-B.; Chen, X.-Y.; Wang, L.-J. 2013b. Isolation and characterization of terpene synthases in cotton (Gossypium hirsutum). Phytochemistry 96: 46-56.

Zhou, M.; Zhang, C.; Wu, Y.; Tang, Y. 2013. Metabolic engineering of gossypol in cotton. Applied Microbiology and Biotechnology 97(14): 6159-6165. 